\title{
ИССЛЕДОВАНИЕ ПОКАЗАТЕЛЕЙ ИННОВАЦИОННОГО РАЗВИТИЯ РОССИИ В УСЛОВИЯХ ЦИФРОВОЙ ЭКОНОМИКИ
}

\author{
(c) 2020 Бекбергенева Дина Евгеньевна \\ кандидат экономических наук, доцент, кафедра теории практики и управления \\ Оренбургский филиал РАНХиГС, Россия, Оренбург \\ E-mail: dinabekber@mail.ru
}

В статье представлены результаты анализа показателей инновационного развития России по сравнению с европейскими странами в условиях цифровой экономики. Особое внимание уделено описанию индикаторов инновационности экономики и изучению структуры затрат на технологические, маркетинговые и организационные инновации в России.

Ключевые слова: инновации, инновационная экономика, технологические инновации, маркетинговые инновации, организационные инновации.

\section{Введение}

Развитие цифровой экономики во всем мире и в России предполагает активное внедрение инноваций не только в информационнокоммуникационной сфере. Промышленность, сельское хозяйство, сфера услуг и торговли нуждаются в постоянном обновлении ассортимента, в модернизации технологий производства и продажи товаров и услуг, во внедрении новых методов продвижения и улучшении способов обслуживания потребителей. Для определения степени инновационного развития стран используют разные показатели, наиболее известный и комплексный - рейтинг инновационных стран мира, составляемый информационноаналитическим агентством Bloomberg.

Агентство анализирует десятки критериев и делит их на семь категорий:

- исследования и разработка, в данном разделе изучаются расходы на исследования и разработки, расчет ведется в\% от ВВП страны;

- производство добавленной стоимости, которая рассчитывается в\% ВВП, приходящееся на душу населения в стране;

- производительность труда (величина выработки и трехлетнее изменение валового внутреннего продукта и валового национального продукта на одного работающего по найму в возрасте старше 15 лет);

- плотность высоких технологий (общее количество работающих в стране компаний в сфере высоких технологий и их доля от общемирового уровня);

- эффективность высшего образования, что предполагает не только измерение общего числа обучающихся в системе высшего образования в стране, независимо от возраста, как процент от количества выпускников школ, но и расчет минимальной доли рабочей силы с высшим образованием;

- концентрация исследователей, то есть научных работников, в том числе аспирантов и соискателей научных степеней, занятых в НИОКР на миллион населения в стране;

- патентная активность (количество патентных заявок, поданных резидентами страны на регистрацию, а также общий объем заявок и действующих патентов, на миллион населения).

Результаты исследования динамики инновационного развития

В 2020 году Германия в этом рейтинге инновационных экономик потеснила Южную Корею, которая была лидером рейтинга шесть лет, и вышла на первое место. В индексе Bloomberg Германия получила три ТОП-5 рейтинга по производству добавленной стоимости (4 место), плотности высоких технологий (3 место) и патентной активности (3 место). Второе место у Южной Кореи, которая утратила первой место из-за относительного падения производительности труда, опустившись в этом показателе за год на 11 позиций (29 место). Сингапур вернулся на третью строчку рейтинга (с шестого места), где он последний раз был в 2018 году. Сингапур занимает первую и вторую позиции по критериям эффективности высшего образования и производства добавленной стоимости. Россия занимает 26-е место в данном рейтинге, находится между Польшей и Малайзией [1].

Структура отдельных видов инновацион- 
ной деятельности, реализуемых организациями в России и Европейских странах, входящих в ТОП-30 по рейтингу инновационных экономик на начало 2020 года представлена на рисунке 1.

Проанализировав структуру затрат на разные виды инновационной деятельности, можно отметить, что только $4,3 \%$ организаций в России проводят маркетинговые исследования, 6,7\% вкладывают средства в изменение дизайна и менее 9\% организаций приобретают новые технологии. В других европейских странах данными видами инновационной деятельности занимаются от $20 \%$ до $50 \%$ организаций. Например, в Германии 24\% организаций проводят маркетинговые исследования, 23\% организаций вкладывают в улучшение дизайна, 19\% организаций постоянно приобретают новые технологии. В России же только приобретение машин и оборудования и программных средств активно развивается, в это направление вкладывают около $66 \%$ организаций.
По оценкам аналитиков ВШЭ по абсолютным расходам на НИОКР Россия занимает 10-е место в мире, в бюджете Российской Федерации на разработки и исследования заложено чуть более 1\% ВВП (это 34-е место в мире). В Южной Корее на научные исследования выделяется $3-4 \%$ от ВВП, в США $-2,74 \%$, в Китае $-2,12 \%$. При этом в России 66\% всех расходов на науку оплачивают государственные источники, 30\% средства предпринимательского сектора, 2,6\% иностранные источники инвестиций [2].

Основными получателями выделенных средств являются бюджетные научноисследовательские институты (1577 институтов в 2017 году, снижение на 5,7\% по сравнению с 2016 годом) и образовательные организации высшего образования (970 организаций в 2017 году, снижение на 1\% по сравнению с 2016 годом) [3].

Динамика доли организаций, осуществляющих технологические инновации, представлена

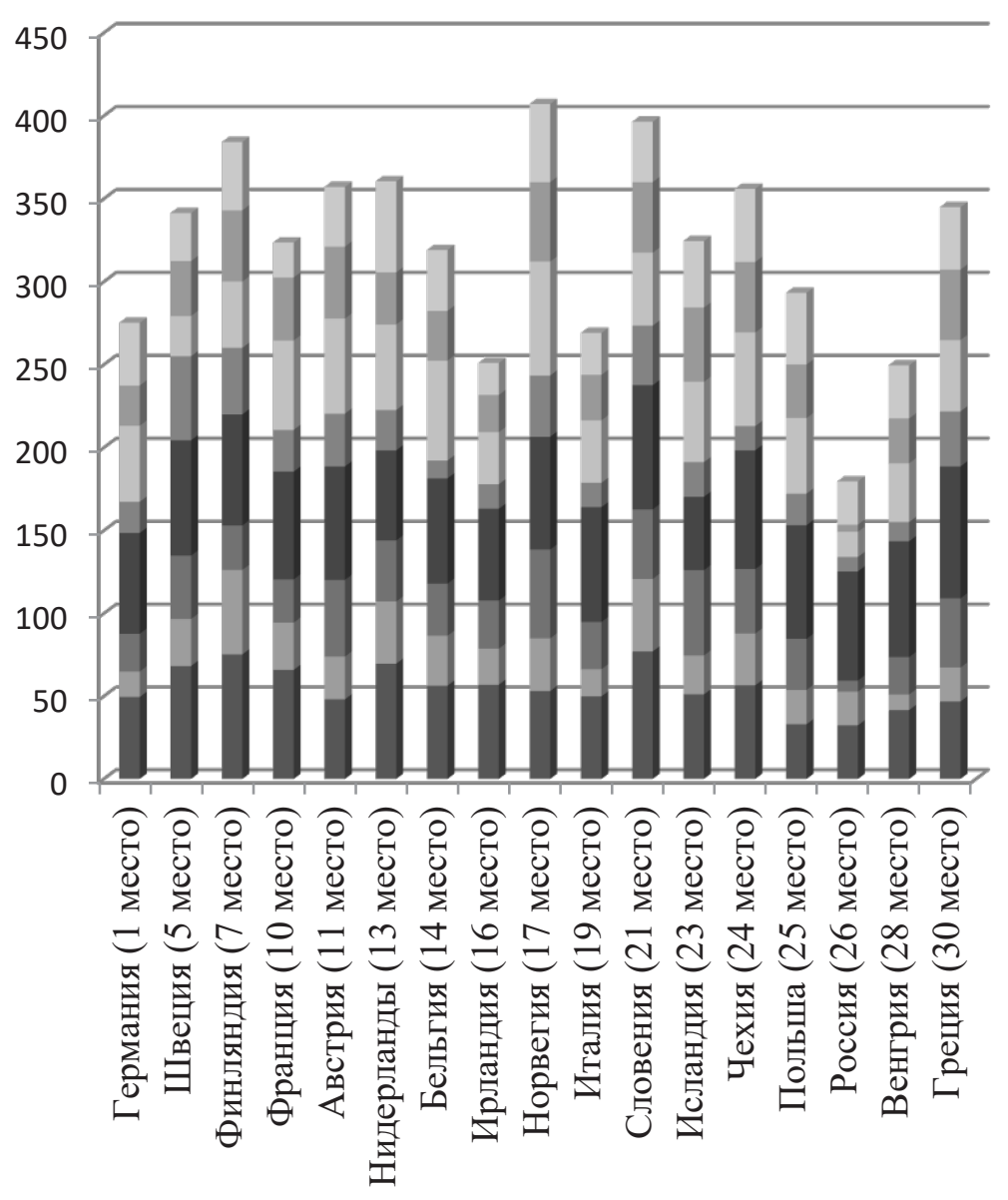

Прочие виды инновационной деятельности

— Маркетинговые исследования

$\square$ Обучение и подготовка персонала

- Приобретение новых технологий

- Приобретение машин и оборудования, программных средств

- Дизайн

- Исследования и разработки, выполненные сторонними организациями

- Исследования и разработки, выполненные собственными силами

Puc. 1. Структура затрат на инновационную деятельность организаций в России и Европейских странах, входящих в ТОП-30 инновационных экономик в 2019 году, \% 
на рисунке 2. При анализе данного показателя необходимо учитывать, что 20 декабря 2019 года приказом № 788 Росстата была обновлена методология расчета доли организаций, осуществляющих технологические инновации, в общем количестве организаций в соответствии с актуализированными международными стандартами измерения инновационной деятельности (новой четвертой редакции международного руководства по статистическому измерению инноваций) [4].

При изучении распределения затрат на инновации по типам, их делят на технологические (продуктовые и процессные), маркетинговые и организационные инновации. Рассмотрим далее структуру затрат на инновации в России в 2017 году [5].

Технологические инновации, включающие продуктовые и процессные инновации, составляют 99\% всех затрат на инновационную деятельность российских предприятий. На рисунке 3 показана структура затрат на технологические инновации в России в 2017 году.

Маркетинговые инновации занимают менее
1\% среди затрат на инновационную деятельность организаций в России, но среди видов экономической деятельности распределение затрат происходит неравномерно, что представлено на рисунке 4. Организационные изменения также составляют менее 1\% в структуре затрат на инновационные изменения российских организаций, хотя по составу эти затраты достаточно разнообразны, что можно увидеть из рисунка 5.

\section{Заключение}

Развитие инновационной активности в России в данное время замедлилось, но в стране есть потенциал для внедрения не только технологических, но и маркетинговых и организационных инноваций. Этому может способствовать рост инвестиций в обрабатывающую промышленность, отрасли сферы услуг, а также вложения в строительный комплекс. Также привлекательными для инвестирования отраслями в России выступают сельское хозяйство и фармацевтическое производство, где можно реализовывать информационно-коммуникационные инновации в рамках развития цифровой экономики.

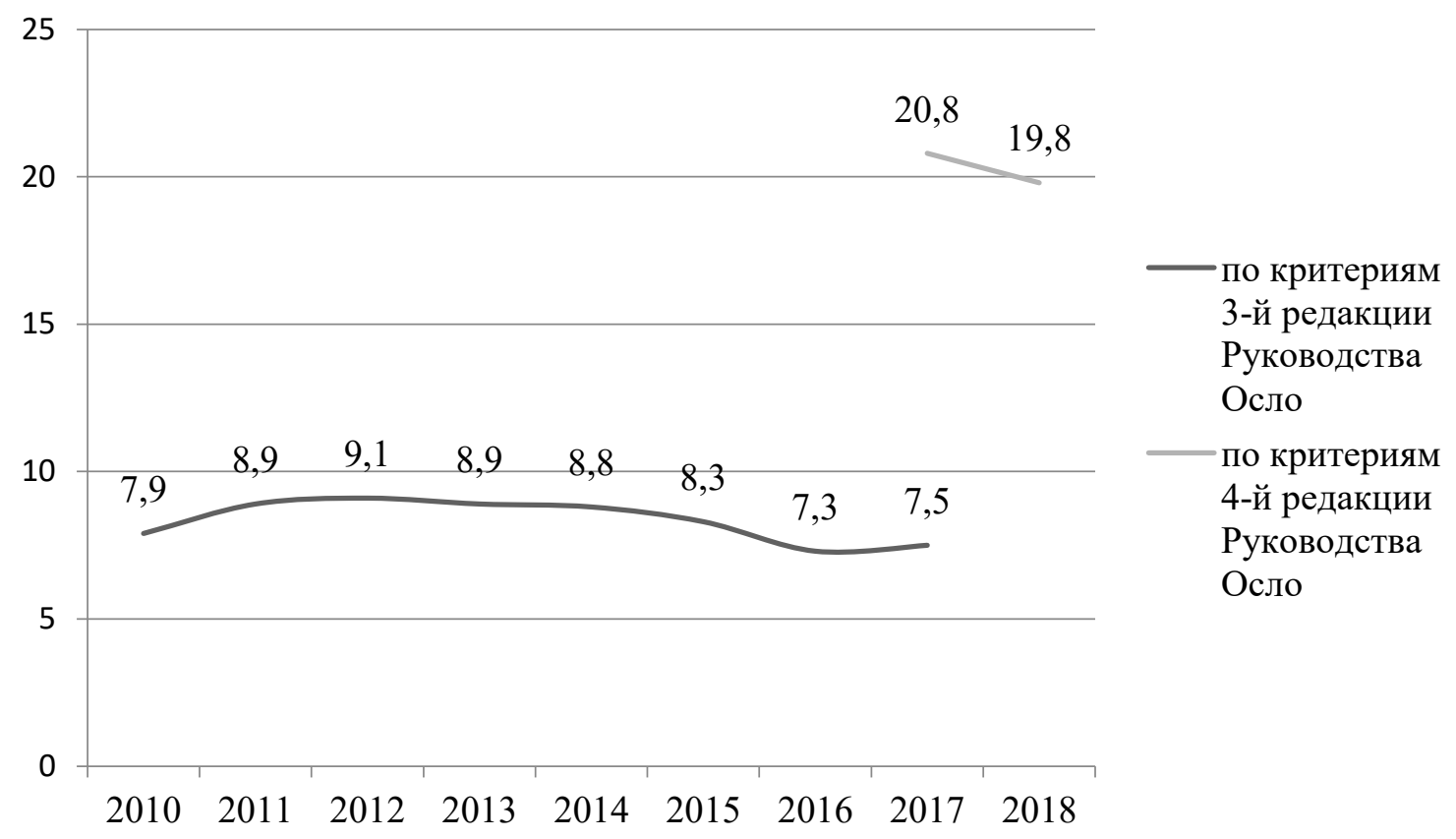

Puc. 2. Динамика количества организаций, осуществляющих технологические инновации в России в 2010-2018 гг., в\% от общего количества организаций (составлено автором) 


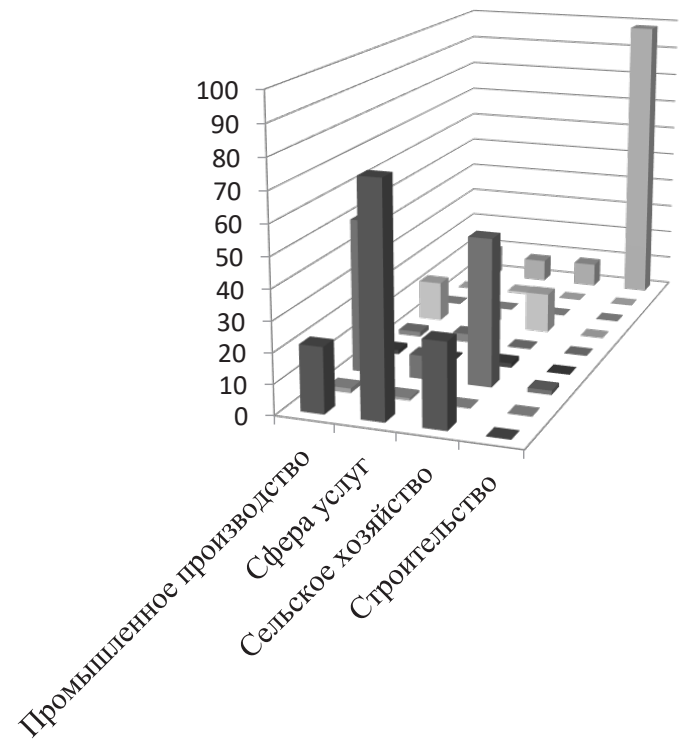

- Исследования и разработки

— Дизайн

- Приобретение машин и оборудования

- Приобретение новых технологий

- Приобретение программных средств

Инжиниринг

- Обучение и подготовка персонала

- Маркетинговые исследования

- Прочие затраты

Puc. 3. Структура затрат на технологические инновации в России в 2017 году, \% (составлено автором)

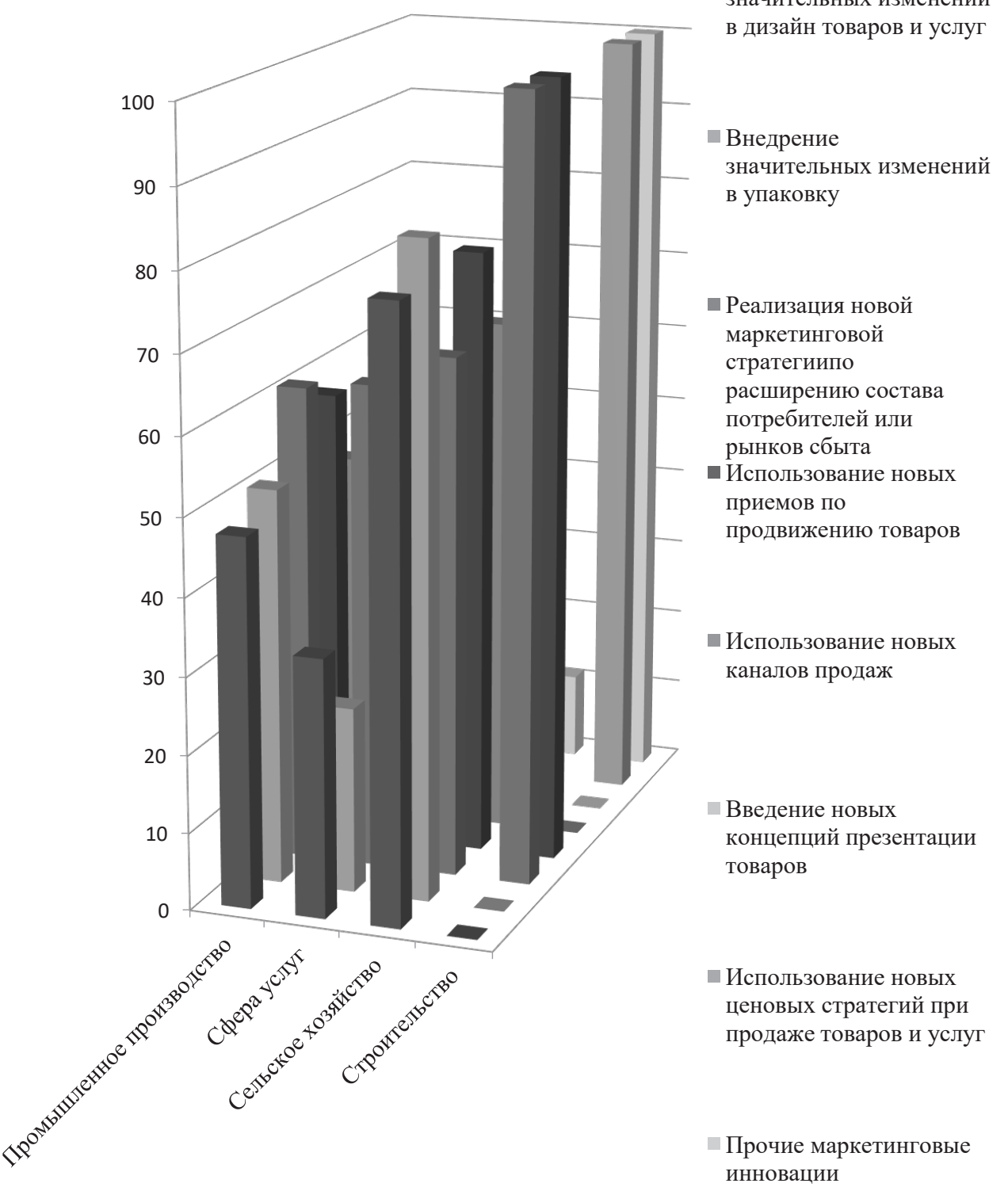

- Внедрение

значительных изменений

в дизайн товаров и услуг

Внедрение

значительных изменений в упаковку

Реализация новой маркетинговой о состава потребителей или приемов по продвижению товаров инновации

Puc. 4. Распределение затрат на маркетинговые инновации по видам экономической деятельности в России в 2017 году,\% (составлено автором) 


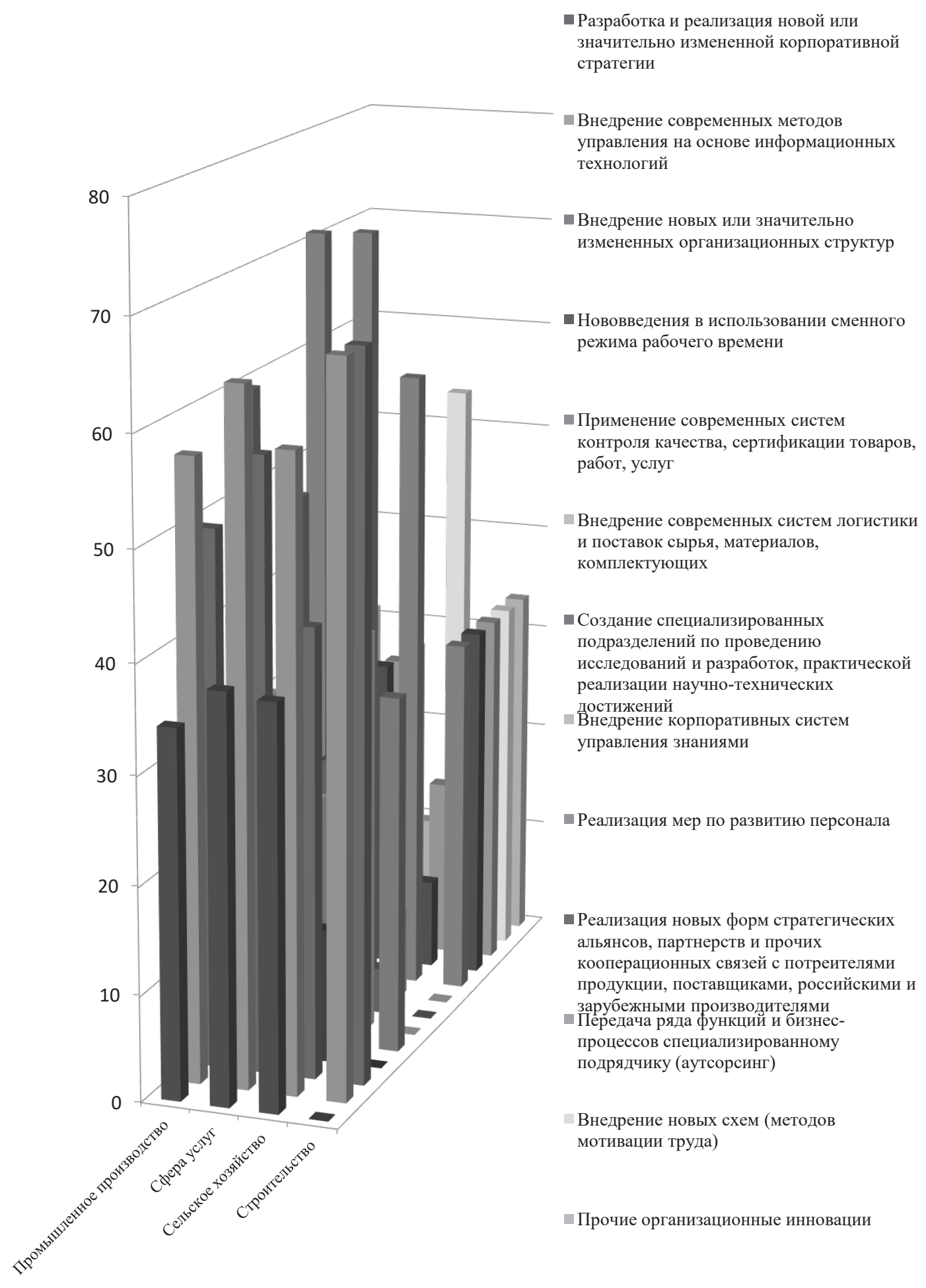

Puc. 5. Распределение затрат на организационные инновации по видам экономической деятельности в России в 2017 году,\% (составлено автором) 


\section{Библиографический список}

1. Рейтинг инновационных экономик: 2020.- Режим доступа: https://theworldonly.org/rejting-innovatsionnyhekonomik-2020/ (дата обращения 09.03.2020).

2. Рейтинг ведущих стран мира по затратам на науку.- Режим доступа: https://issek.hse.ru/press/221888720. $\mathrm{html}$ (дата обращения 09.03.2020).

3. Наука. Технологии. Инновации: 2019: краткий статистический сборник / Н.В. Городникова, Л.М. Гохберг, К.А. Дитковский и др.; Нац. исслед. ун-т «Высшая школа экономики».- Москва: НИУ ВШЭ, 2019-84 с. - Режим доступа: https://www.hse.ru/data/2018/12/11/1144786145/niio2019.pdf (дата обращения 11.03.2020).

4. Приказ Федеральной службы государственной статистики РФ от 20 декабря 2019 года № 788 «Об утверждении Методики расчета показателя «Удельный вес организаций, осуществляющих технологические инновации, в общем числе обследованных организаций»».- Режим доступа: http://docs.cntd.ru/document/564192785 (дата обращения 11.03.2020).

5. Индикаторы инновационной деятельности: 2019: статистический сборник / Л.М. Гохберг, К.А. Дитковский, И.А. Кузнецова и др.; Нац. исслед. ун-т «Высшая школа экономики». - Москва: НИУ ВШЭ, 2019. - 376 с.Режим доступа: https://www.hse.ru/data/2019/05/06/1501882833/ii_2019.pdf (дата обращения 10.03.2020). 